\title{
IMAGENS DO IMPERADOR DO JAPÃO UMA ANÁLISE DISCURSIVA DE ALOCUÇÕES DE AKIHITO
}

Raphael dos Santos Miguelez Perez é atualmente professor substituto do Setor de Letras Japonesas da UFRJ e integrante do Programa Brasil-Japão da Uerj. Possui mestrado em Letras (área de concentração: Linguística) pela Uerj e graduação em Letras Português/Japonês pela mesma instituição.

E-mail: raphael.kaworu@gmail.com

\section{Resumo}

Levando em consideração o atual status simbólico do Imperador do Japão, o presente artigo busca analisar que imagem Akihito cria de si por meio de suas alocuções, que se encontram disponíveis no site da Agência da Casa Imperial, tanto em japonês quanto em inglês. A análise se baseia nas perspectivas da Análise do Discurso de base enunciativa e nas considerações foucaultianas a respeito de relações de poder. Este artigo representa parte de minha dissertação de mestrado, defendida em 2013.

\begin{abstract}
Considering the present symbolic status of the Emperor of Japan, the following article aims to analyze what image Akihito creates of himself through his speeches, which are available at the Imperial Household Agency website, both in Japanese and in English. The analysis is based on the perspective of the Discourse Analysis of enunciative basis and on Foucault's considerations on power relations. This article is part of my Master's dissertation, finished in 2013.
\end{abstract}

\section{1) Introdução}

A instituição imperial japonesa e a figura do Imperador do Japão possuem relação direta com a história do país. Considerados mitologicamente como descendentes divinos e ligados à formação do arquipélago nipônico, os imperadores já reinaram como sacerdotes, mecenas, guerreiros, e também já estiveram isolados por séculos quando do governo dos xoguns (cf. MARTIN, 1997, p.3). Com a chamada Restauração Meiji, em 1868, a família imperial e o Imperador retornam ao governo da nação japonesa (cf. KURIHARA; NISHIZAWA, 2009, p. 196), sob uma Constituição absolutista que afirmava a descendência divina do Imperador e sua soberania. Foi sob essa Constituição que o Japão ingressou na Segunda Guerra Mundial ao lado da Alemanha de Hitler e da Itália de Mussolini.

Após a derrota do Japão na guerra, levando à ocupação americana do território japonês, o então Imperador Hirohito se viu obrigado a renunciar ao seu status de divindade, bem como a se submeter a uma nova Constituição, promulgada em 1947, que lhe retirava a soberania e o definia como símbolo da nação e da união do povo japonês. Akihito, filho de Hirohito e atual Imperador do Japão, assumiu o trono em 1989 já sob essa Constituição que previa um imperador simbólico.

Levando em consideração o caráter dessa função simbólica do Imperador do Japão, mais precisamente de Akihito, busca-se refletir, no presente artigo, a respeito da imagem discursiva criada pelo monarca, ou seja, a imagem que ele cria de si ao enunciar. Para tal, foram analisadas duas alocuções de Akihito obtidas em conferências de imprensa por um viés foucaultiano de relações de poder.

Cabe ressaltar que os termos em língua japonesa utilizados na pesquisa seguem o padrão de romanização sugerido pelos pesquisadores de língua, literatura e cultura japonesa da Universidade de São Paulo, como consta nos artigos publicados no periódico Estudos Japoneses, publicado desde 1979. 


\section{2) Imagens discursivas: o conceito de etos ${ }^{1}$}

O conceito de etos apresentado aqui segue os pressupostos teóricos de Dominique Maingueneau, que afirma:

$\mathrm{Na}$ perspectiva da análise do discurso, não podemos, pois, contentar-nos, como a retórica tradicional, em fazer do ethos um meio de persuasão: ele é parte constitutiva da cena de enunciação, com o mesmo estatuto que o vocabulário ou os modos de difusão que o enunciado implica por seu modo de existência. (MAINGUENEAU, 2011, p. 75)

O autor se refere ao conceito de etos pensado sob uma ótica aristotélica, que o define como sendo um instrumento de persuasão do orador. Para Maingueneau, no entanto, etos é a imagem que o enunciador cria de si por meio da forma como enuncia, de sua postura, de sua aparência e de um modo de dizer, que implica um modo de ser. Essa imagem independe da vontade desse enunciador. Assim, entende-se que o etos não depende do que é dito de fato, mas do que é mostrado por meio da forma como se enuncia.

Nesse sentido, se se entende etos como uma imagem que se cria a partir de determinada forma de enunciar, independente da vontade do enunciador, parece evidente, portanto, que cabe ao coenunciador a responsabilidade pela criação dessa imagem, ou seja, do etos do enunciador. Trata-se da forma como o coenunciador apreende e incorpora essa imagem discursiva de quem enuncia.

Importante observar também que o etos, diferente da perspectiva aristotélica supracitada, não será preferencialmente apreendido por meio da oralidade, mas também por meio da escrita, pois em ambas as formas de enunciação pode-se apreender um tom, uma imagem de enunciador. A presente pesquisa, por exemplo, busca analisar o etos do Imperador Akihito por meio de suas alocuções escritas.

\section{3) As relações de poder}

Levando-se em consideração que se busca aqui pensar a imagem do Imperador do Japão por meio de uma perspectiva foucaultiana, cabe uma discussão breve do que o autor entende por poder, visto que se busca pensar também o sistema imperial simbólico japonês por meio dessa perspectiva.

Costuma-se pensar o poder como algo que alguém ou alguma instituição possui. Tal pensamento sugere uma verticalidade do poder, que seria conferido a alguém ou a alguma instituição de forma que se concentre no topo de uma pirâmide que representaria um grupo social em uma dada hierarquia. Essa concepção senso-comum de poder, entretanto, difere da proposta por Foucault.

\footnotetext{
${ }^{1}$ Optou-se no presente artigo por grafar o termo etos da forma como se encontra dicionarizado em língua portuguesa.
} 
As relações de poder se enraízam no conjunto da rede social. Isto não significa, contudo, que haja um princípio de poder, primeiro e fundamental, que domina até o menor elemento da sociedade; mas que há, a partir dessa possibilidade de ação sobre a ação dos outros [...], múltiplas formas de disparidade individual, de objetivos, de determinada aplicação do poder sobre nós mesmos e sobre os outros, de institucionalização mais ou menos setorial ou global, organização mais ou menos refletida, que definem formas diferentes de poder. As formas e os lugares de "governo" dos homens uns pelos outros são múltiplos numa sociedade: superpõem-se, entrecruzam-se, limitam-se e anulam-se, em certos casos, e reforçam-se em outros. É certo que o Estado nas sociedades contemporâneas não é simplesmente uma das formas ou um dos lugares - ainda que seja o mais importante - de exercício do poder, mas que, de um certo modo, todos os outros tipos de relação de poder a ele se referem. (FOUCAULT, 1995, p. 247)

Nesse sentido, não se possui poder e este não se concentra em um único ponto, de onde exerce sua influência de forma vertical e opressora. O poder não está exclusivamente em determinado lugar, ele circula por toda uma rede de relações sociais de forma horizontal, atravessando todos os membros e setores de uma sociedade. Onde há relações entre seres humanos, há necessariamente relações de poder. Não existe sociedade sem relações de poder. Assim, não seria pertinente afirmar que o Imperador do Japão não possui poder político por se tratar de um Imperador simbólico, visto que não há como os sujeitos não estarem investidos de poder.

De forma a melhor ilustrar as relações de poder e como elas se dão na sociedade japonesa, podemos nos pautar no conceito de "friendly authoritarianism" (em tradução livre, "autoritarismo amigável”), segundo Sugimoto (1997, p. 245). "Autoritarismo" no sentido em que encoraja cada membro da sociedade a internalizar e compartilhar um sistema de valores em termos de controle e ordem tidos como naturais, sem muitos questionamentos a respeito; "amigável" no sentido em que não se dá de forma coerciva, exercendo-se como incentivos leves. Sugimoto (p. 257) exemplifica sua teoria de “autoritarismo amigável" por meio de quatro categorias, a saber: 1) vigilância mútua em pequenos grupos (registros familiares, associações de bairro etc.); 2) poder visível e tangível (postos policiais, horas excessivas de trabalho, visita dos professores nas residências de seus alunos etc.); 3) ambiguidade manipulativa (Constituição, prática de troca de presentes, publicação de materiais didáticos aprovados pelo governo etc.); 4) correção mental e moral (cartas de pedido de desculpas, limpeza das salas de aula por parte dos alunos, necessidade de estar em compasso com os valores morais vigentes etc.). Tais práticas corroboram a tese de Foucault de uma rede de poderes enraizados na sociedade.

Embora Sugimoto não trate em nenhum momento do conceito de poder de acordo com a ótica foucaultiana de forma explícita, sua teoria do "autoritarismo amigável" ilustra bem o conceito de poder como se entende no presente artigo, visto que trata de questões como a mútua vigilância na sociedade, por exemplo, em consonância com o que se discute aqui. Isso reafirma essa natureza vigilante das relações de poder.

Foucault ainda trata de uma função econômica do poder:

Mas o corpo também está diretamente mergulhado num campo político; as relações de poder têm alcance imediato sobre ele; elas o investem, o marcam, o dirigem, o 
supliciam, sujeitam-no a trabalhos, obrigam-no a cerimônias, exigem-lhe sinais. Este investimento político do corpo está ligado, segundo relações complexas e recíprocas, à sua utilização econômica; é, numa boa proporção, como força de produção que o corpo é investido por relações de poder e de dominação; mas em compensação sua constituição como força de trabalho só é possível se ele está preso num sistema de sujeição (onde a necessidade é também um instrumento político cuidadosamente organizado, calculado e utilizado); o corpo só se torna força útil se é ao mesmo tempo corpo produtivo e corpo submisso. (FOUCAULT, 2010, p. 28-29)

De acordo com o trecho acima, Foucault apresenta uma função econômica das relações que investem o sujeito de poder. Trata-se de uma característica das relações de poder que desde a era do Iluminismo se manifesta em prol de uma ordem social que tenha como base o trabalho. Tal consideração possibilita que se compreenda o poder enquanto um poder disciplinar, em prol de uma ordem econômica.

Assim, considerando-se o poder enquanto detentor de caráter disciplinar, parece natural compreender que, para que se mantenha determinada ordem social, faz-se necessária constante vigilância, exercida por meio de todos os membros dessa rede de relações de poder. Essas considerações de Foucault parecem se aplicar muito bem na sociedade japonesa, na qual se tem o trabalho e a cooperação como motores dessa sociedade. O Imperador enquanto símbolo da nação e da união do povo nipônico, por sua vez, serve de incentivo a esses valores.

A sociedade como entendemos hoje, então, se estrutura de forma tal que as relações de poder se verificam em toda parte, configurando-se em uma rede de micropoderes e exercendo-se por meio de dispositivos disciplinantes, os quais garantem a ordem social a favor da força econômica que impera enquanto motor para o pleno funcionamento do mundo capitalista.

E aquilo que se deve compreender por disciplinarização das sociedades, a partir do século XVIII na Europa, não é, sem dúvida, que os indivíduos que dela fazem parte se tornem cada vez mais obedientes, nem que elas todas comecem a se parecer com casernas, escolas ou prisões; mas que se tentou um ajuste cada vez mais controlado cada vez mais racional e econômico - entre as atividades produtivas, as redes de comunicação e o jogo das relações de poder. (FOUCAULT, 1995, p. 242)

À guisa de exemplificação desse caráter econômico das relações de poder, encontra-se em Field (1993) uma relação entre o sistema imperial simbólico japonês e o capitalismo.

O estilo doméstico do novo casal, Akihito e Michiko, foi amplamente difundido por meio da televisão e das revistas femininas. Tratava-se de um lar atraente, florescendo sob a contemplação benevolente do imperador e da imperatriz, que seguiam envelhecendo. A imagem se dirigia aos jovens do Japão: trabalhem duro e vocês, também, podem um dia ter uma sala de estar onde as crianças tocam instrumentos musicais e leem livros junto a seus pés. ${ }^{2}$ (FIELD, 1993, p. 26)

\footnotetext{
${ }^{2}$ Tradução livre de: The domestic style of the new couple, Akihito and Michiko, was widely disseminated through television and women's magazines. It was an appealing household, blossoming under the gaze of the benevolently aging emperor and empress. The image called out to the youth of Japan: work hard and
} 
Trata-se do casamento entre o então Príncipe Herdeiro Akihito e Michiko, em 1959, época em que a televisão estava começando a se difundir pelo Japão. Para assistir à cerimônia, muitas famílias japonesas adquiriram um aparelho de televisão, impulsionando a venda do produto no país e tornando-o um dos principais meios de comunicação da época. Fica evidente também a influência de um modo de ser e viver da família imperial sobre a população nipônica. A ideia de família feliz e unida, como descreve Field, pode servir de modelo para a população, além de incentivar a dedicação do povo ao trabalho, o que gera força econômica, que impulsiona a economia do país e, por sua vez, configura um modo contemporâneo de estímulo ao consumo, garantindo estabilidade de um modelo capitalista de sociedade.

Essas considerações, portanto, ilustram o modo sobre como as relações de poder são exercidas na sociedade nipônica.

\section{4) Metodologia de pesquisa e análise}

O corpus de análise do presente artigo foi coletado no endereço eletrônico da Agência da Casa Imperial, instituição responsável pela administração e por quaisquer assuntos relativos à família imperial japonesa. $\mathrm{O}$ site apresenta assuntos referentes à família imperial e ao imperador, notícias sobre as atividades de seus membros, bem como todas as alocuções oficiais de cada um deles, incluindo, naturalmente, as do Imperador Akihito.

Optou-se por fazer um recorte das alocuções de Akihito realizadas nas conferências de imprensa, ocasião que proporciona assuntos diversos, justificando o interesse por essa categoria. Mais precisamente, foram analisadas as conferências de imprensa comemorando os dez e os vinte anos de reinado de Akihito, respectivamente 1999 e 2009, realizadas em conjunto com o Imperador e com a Imperatriz, interessando para esta pesquisa, no entanto, apenas as alocuções do primeiro.

Considerando que o sítio eletrônico da Agência da Casa Imperial oferece duas versões dessas alocuções, uma em japonês e a outra em inglês, entende-se que a última é direcionada à comunidade internacional, enquanto a primeira se volta para o povo japonês e para aqueles que dominem o idioma. Pensando nisso, buscou-se realizar uma análise contrastiva entre as duas versões, verificando se havia diferenças entre as alocuções originais de Akihito e suas traduções disponíveis no sítio eletrônico em questão.

Das alocuções selecionadas, foram destacadas as ocorrências do verbo em língua japonesa omou (achar; pensar; sentir). Tal escolha se deve à grande quantidade de ocorrências desse verbo nas alocuções de Akihito, indicando tanto julgamento quanto sentimento. Além disso, seu uso como atenuador de um desejo ou de uma opinião

you, too, may one day have a living room where children play musical instruments and read books at your knee. (FIELD, 1993, p. 26) 
também justificam essa escolha, característica da língua japonesa, como apontam Makino e Tsutsui (2003, p. 52).

Importante observar, entretanto, que não se objetiva aqui nem julgar a qualidade da tradução oferecida no endereço eletrônico da Agência da Casa Imperial, nem tratar das intenções dos enunciadores (o que não se configura como foco da Análise do Discurso de base enunciativa), mas mostrar concretamente que algumas diferenças entre o original em japonês e a versão em inglês podem contribuir para a criação de etos distintos do Imperador Akihito. Não se trata, portanto, de um trabalho com foco na qualidade da tradução e na intencionalidade dos enunciadores, mas na produção de sentidos em nível discursivo. Apesar disso, são oferecidas propostas de tradução do japonês para português, de forma que possibilite ao leitor que não domine nenhum dos dois idiomas que compreenda melhor as questões discutidas neste artigo. E reforça-se que, apesar de o autor desta pesquisa não ser falante nativo nem de japonês, nem de inglês, este se baseia em seu conhecimento aprofundado dos dois idiomas e em suas leituras a respeito do assunto aqui abordado, tendo como base as referências apresentadas no final do artigo, bem como outras leituras complementares, utilizadas na dissertação de mestrado na qual esta pesquisa foi apresentada.

Ressaltamos, também, que todos os grifos nos trechos analisados são nossos. Além disso, cabe explicar que o número das questões e os anos apresentados em cada ocorrência de análise correspondem ao número da pergunta na conferência de imprensa e ao ano em que foi realizada, conforme consta no site da Agência da Casa Imperial.

\section{1) Análise das ocorrências de omou expressando sentimento}

No caso do verbo omou expressando sentimento, foram registradas treze ocorrências, das quais cinco apresentam diferenças mais ou menos significativas entre as duas versões. Um quadro explicativo foi acrescentado logo em seguida às ocorrências. Cabe acrescentar que é interessante que o leitor repare nas construções em japonês (ou na proposta de tradução para o português) e as compare com a construção de sentido em inglês.

\section{Ocorrências 1 e 2:}

Original: Keizai jôkyô no kibishii naka de oiwai o shite kudasaru koto o kokorogurushiku omotte imashita ga, oiwai no kimochi ni wa fukaku kanshashi, ureshiku omotte imasu.

Tradução oficial: Although it has weighed on my conscience that there should be celebrations under the present stringent economic circumstances, I am nonetheless deeply grateful for the good wishes extended to me on this occasion and appreciate them. (Questão 1, 1999)

Proposta de tradução para português: Apesar de me sentir constrangido com o fato de haver comemorações [de dez anos de reinado] em meio a condições econômicas severas, agradeço profundamente os sentimentos festivos e me sinto feliz com o carinho. (Grifo nosso) 


\section{Ocorrência 3:}

Original: Bôsai ni atatte iru hitobito no itazuki o kokoro kara negiraitaku omoimasu.

Tradução oficial: I deeply appreciate the efforts made by those who are engaged in disaster prevention activities. (Questão 2, 1999)

Proposta de tradução para português: Agradeço de coração o esforço daqueles que estão dedicados à prevenção de desastres.

\section{Ocorrência 4:}

Original: Watakushidomo ga sono yôna kokoro no sasae ni kiyosuru koto ga dekireba to omotte imasu.

Tradução oficial: It is my hope that we can be of some help in providing moral support. (Questão 2, 1999)

Proposta de tradução para português: $\underline{\text { Sinto que seria bom se pudéssemos contribuir }}$ oferecendo apoio moral.

\section{Ocorrência 5:}

Original: Chûgoku o nozoite wa, Kôtaishi no toki hômonshita kuniguni deshita ga, Nihon to sorezore no kuni to no kôryû ga issô susunde kite iru koto ga kanjirare, ureshiku omoimashita. Tradução oficial: I had visited these countries when I was Crown Prince, with the exception of the People's Republic of China, and I was encouraged by the fact that exchange between Japan and each of these countries seemed to be steadily increasing. (Questão 4, 1999)

Proposta de tradução para português: Visitei esses países quando era Príncipe Herdeiro, com exceção da China, e me senti feliz ao sentir que as relações entre o Japão e esses países vinham progredindo cada vez mais.

\section{Ocorrência 6:}

Original: Sorezore no kuni no ayunde kita michi wa chigaimasu ga, hitobito no kimochi ni wa kokkyô o koete hijô ni chikai mono ga aru yô ni omoimasu.

Tradução oficial: Each of these countries has taken a different path, but it seems to me that people's feelings are very similar across national borders. (Questão 4, 1999)

Proposta de tradução para português: Os caminhos que cada país vem trilhando são diferentes, mas sinto como se os sentimentos das pessoas fossem muito próximos, transpondo fronteiras nacionais.

\section{Ocorrência 7:}

Original: Ato ni hoka no hisaichi o otozureta toki, jibuntachi no saigai ni shien no te o sashinobete moratta no de, orei no kimochi de kono hisaichi no shien ni kita to iu hitobito ni au koto ga ari, tanomoshiku omoimashita.

Tradução oficial: When I visited other regions affected by natural disasters, I was heartened to meet people who said that, having received help themselves as victims of disasters, they were now coming to help others in similar circumstances. (Questão 1, 2009)

Proposta de tradução para português: Quando posteriormente visitei as regiões afetadas por desastres naturais, me senti encorajado ao encontrar com pessoas que disseram que tinham vindo para ajudar nessas regiões em forma de agradecimento, já que haviam recebido ajuda em ocasiões em que elas mesmas tinham sido vítimas de desastres. 


\section{Ocorrência 8:}

Original: Sono yôna naka de, kôreisha ya kaigo o hitsuyô to suru hitobito no koto o kokoro ni kake, sasaete ikô to iu hitobito ga ôku natte kite iru yô ni kanjirare, kokorozuyoku omotte imasu. Tradução oficial: It is encouraging to see, at a time like this, that there seems to be an increasing number of people who care about the elderly and those in need of nursing and who are making efforts to support them. (Questão 1, 2009)

Proposta de tradução para português: Nesses momentos, me sinto encorajado ao perceber que vem aumentando o número de pessoas que se importam com os idosos e com aqueles que necessitam de apoio, e que pretendem continuar prestando auxílio a eles.

\section{Ocorrência 9:}

Original: Heisei ga 20 nen to nari, ôku no hitobito ga oiwai no kimochi o arawashite kureru koto o ureshiku omoi, kanshashite imasu.

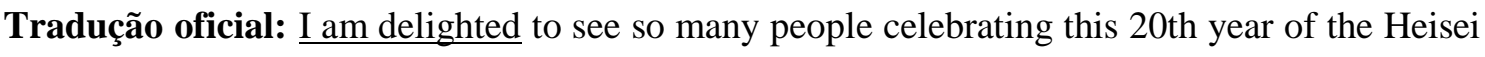
Era. (Questão 1, 2009)

Proposta de tradução para português: Fico feliz e agradeço às inúmeras pessoas que demonstram seus sentimentos de celebração dos vinte anos da Era Heisei.

\section{Ocorrência 10:}

Original: Itsu no jidai ni mo, shinpai ya fuan wa arimasu ga, wakai hitobito no ibuki o ureshiku kanjitsutsu, kore kara no Nihon o mimamotte ikitai to omoimasu.

Tradução oficial: Whatever the times, there are always fears and anxieties, but while rejoicing in the vigour of the younger generation, I will continue to watch over Japan. (Questão 3, 2009)

Proposta de tradução para português: Seja em que era for, sempre haverá preocupações e inseguranças, mas, me sentindo feliz com o vigor dos jovens, gostaria de seguir olhando pelo Japão.

\section{Ocorrência 11:}

Original: Mina ga watakushidomo no kenkô o shinpaishite kurete iru koto ni, mazu kanshashitai to omoimasu.

Tradução oficial: First of all, I would like to express my appreciation for everyone's concern over my health. (Questão relacionada, 2009)

Proposta de tradução para português: Primeiramente, gostaria de agradecer a todos por estarem preocupados com a nossa saúde.

\section{Ocorrência 12:}

Original: Shikashi, kono jôkyô wa, ima no jôkyô naraba, sono mama tsuzukete ikitai to omotte orimasu.

Tradução oficial: However, if my health continues as it is, I should like to continue with the current level of official commitments. (Questão relacionada, 2009)

Proposta de tradução para português: Entretanto, se minha saúde permanecer como está, gostaria de continuar dessa forma [mantendo os compromissos oficiais]. (Grifo nosso)

\section{Ocorrência 13:}


Original: Mata, Kôgô no hô mo ashi no hô ga mukashi no yô ni, dandan to yoku natte kite iru yô desu no de, hijô ni ureshiku omotte imasu.

Tradução oficial: As for The Empress, I am very happy to know that her knee is recovering. (Questão relacionada, 2009)

Proposta de tradução para português: E no que diz respeito à Imperatriz, estou muito feliz por sua perna aparentar estar melhorando cada vez mais, ficando como era antes.

Quadro 1: Resumo das ocorrências de omou expressando sentimento

\begin{tabular}{|l|l|l|}
\hline Ocorrência & Sentido em japonês & Sentido em inglês \\
\hline 1 & Pesar / Constrangimento & Pesar / Constrangimento \\
\hline 2 & Felicidade & Felicidade \\
\hline 3 & Gratidão & Gratidão \\
\hline 4 & Desejo & Esperança (mais distante) \\
\hline 5 & Felicidade & Coragem (mais motivado) \\
\hline 6 & Impressão & Impressão \\
\hline 7 & Confiança e coragem & Confiança e coragem \\
\hline 8 & Coragem & Coragem (mais generalizada) \\
\hline 9 & Felicidade & Felicidade (mais ênfase) \\
\hline 10 & Desejo & Promessa (mais enfático) \\
\hline 11 & Gratidão & Gratidão \\
\hline 12 & Desejo & Desejo \\
\hline 13 & Felicidade & Felicidade \\
\hline
\end{tabular}

Conforme observado, essa parte da análise apresenta algumas diferenças entre as alocuções em japonês e em inglês. Enquanto em japonês há maior ocorrência de expressão de desejos e de sentimentos, além de sugerir maior envolvimento do Imperador com aquilo que diz, na tradução para o inglês, por sua vez, parece haver menor envolvimento emotivo, porém maior presença de noções variadas como de esperança, de coragem, de confiança e de promessa, além de mais ênfase naquilo que enuncia.

Nesse sentido, a partir da versão original em japonês, é possível supor uma imagem de um Imperador mais humano e amigo do povo, considerando que demonstra mais suas emoções, o que o humaniza; diferente de seu pai, Hirohito, que, tido como divindade, não tinha contato com o povo até o período do fim da II Guerra Mundial. Essa imagem mais humana de Akihito reforça a ideia de "autoritarismo amigável" de Sugimoto, além de corroborar a noção de relações de poder horizontalizadas de Foucault. Ao passo que, para a comunidade internacional, esse Imperador parece soar mais distante e menos sentimental, porém mais enfático e assertivo, características essas não presentes nas alocuções originais. Essa imagem um pouco mais distante sugere um apelo menor às emoções do povo. Lembrando dos episódios da guerra, quando muitos japoneses afirmaram lutar em nome do Imperador, não haver sugestão de devoção por parte do povo em relação a um monarca parece assegurar que o Japão não representa 
riscos para a comunidade internacional. Novamente se verifica aí a noção de vigilância, segundo Foucault.

\section{2) Análise das ocorrências de omou expressando julgamento}

No caso do verbo omou expressando julgamento, foram registradas dezenove ocorrências, das quais treze apresentam diferenças mais ou menos significativas entre as duas versões. Novamente, é apresentado um quadro comparativo logo após as ocorrências. Reforça-se, ainda, que é interessante que o leitor repare nas construções em japonês (ou na proposta de tradução para o português) e as compare com a construção de sentido em inglês, atentando para a utilização ou não de determinados termos, de forma que fiquem mais claras as diferenças apresentadas no quadro comparativo.

\section{Ocorrência 1:}

Original: Sono yôna atarashii ugoki ni taiôsuru ni wa, ôku no konnan ga aru koto to omoimasu ga, kako ni ikuta no konnan ya shôgai o norikoete kita Nihon no rekishi o omoiokoshi, kokumin hitorihitori no eichi to kokusai shakai no kyôryoku ni yori, korera no konnan ga rippa ni kokufukusarete iku koto o shinjite imasu.

Tradução oficial: There must be numerous difficulties in coping with these new developments, but, as I recall the history of Japan and how in the past so much hardship and distress has been overcome, I firmly believe that the wisdom of each and every Japanese and cooperation from international society will tide us over them in fine style. (Questão 1, 1999)

Proposta de tradução para português: Creio que haja diversas dificuldades para lidar com essas novas mudanças, mas, lembrando da história do Japão, que no passado atravessou inúmeras dificuldades e obstáculos, acredito que, por meio da cooperação da sociedade internacional e da sabedoria de cada cidadão japonês, essas dificuldades continuarão sendo superadas de forma esplêndida.

Ocorrência 2:

Original: Shôgaisha ya kôreisha, saigai o uketa hitobito, arui wa shakai ya hitobito no tame ni tsukushite iru hitobito ni kokoro o yosete iku koto wa, watakushidomo no taisetsuna tsutome dearu to omoimasu.

Tradução oficial: I consider it an important duty of ours to be close in our hearts to the disabled, the elderly and those who suffer from disaster, as well as those who are dedicating themselves to others or society as a whole. (Questão 2,1999)

Proposta de tradução para português: Acho que é um dever importante nosso seguirmos auxiliando os deficientes, os idosos, as vítimas de desastres e também aqueles que se dedicam a fazer algo pelas pessoas e pela sociedade.

\section{Ocorrência 3:}

Original: Watakushidomo no shite kita koto wa katsudô to iu kotoba de iiarawasu koto wa dekinai to omoimasu ga, otozureta shisetsu ya hisaichi de atta hitobito to sukoshi demo kokoro o tomo ni shiyô to tsutomete kimashita.

Tradução oficial: We cannot really describe what we have done in this regard as "activities." What we have tried to do as much as possible is to share our hearts with the people we meet at the facilities and disaster areas we visit. (Questão 2, 1999) 
Proposta de tradução para português: Acho que não podemos descrever aquilo que viemos fazendo como "atividades", mas temos nos dedicado a oferecer pelo menos um pouco de nossos corações às pessoas que encontramos em locais de desastres e em instituições que visitamos.

\section{Ocorrência 4:}

Original: Kyô no Nihon ga kyôjushite iru heiwa to han'ei wa, kono yôna ôku no gisei no ue ni kizukareta mono dearu koto o kokoroshinai to ikenai to omoimasu.

Tradução oficial: $\underline{I}$ think we should all be aware that the peace and prosperity we currently enjoy in Japan was built on the sacrifice of so many such people. (Questão 3, 1999)

Proposta de tradução para português: Acredito que é preciso ter em mente que a paz e a prosperidade das quais o Japão de hoje desfruta foram construídas sobre numerosos sacrifícios desse tipo.

\section{Ocorrência 5:}

Original: Kono yôna kunan no michi o ayumi, Nihon e no fukki o negatta Okinawa kenmin no kimochi o nihonjin zentai ga kesshite wasurete wa naranai to omoimasu.

Tradução oficial: $\underline{I}$ believe that all the people of Japan should never forget the feelings of the people of Okinawa Prefecture who trod such a path of suffering and aspired to reversion to Japan. (Questão 3, 1999)

Proposta de tradução para português: Creio que todos os japoneses não podem esquecer de forma alguma dos sentimentos das pessoas da província de Okinawa, que trilharam um caminho de sofrimento e desejaram sua devolução ao Japão.

\section{Ocorrência 6:}

Original: Watakushi ga Okinawa no rekishi to bunka ni kanshin o yosete iru no mo, fukki ni atatte Okinawa no rekishi to bunka o rikaishi, kenmin to kyôyûsuru koto ga kenmin o mukaeru watakushidomo no tsutome da to omotta kara desu.

Tradução oficial: I have maintained an interest in the history and culture of Okinawa because I felt it our duty, in welcoming the people of Okinawa on the occasion of the reversion, to understand and share with them the history and culture of Okinawa. (Questão 3, 1999)

Proposta de tradução para português: Tenho nutrido um interesse pela história e cultura de Okinawa porque, ao recebê-los na ocasião da devolução [de Okinawa ao Japão], julguei ser nosso dever compreender e compartilhar com eles a história e a cultura de Okinawa. (Grifo nosso)

\section{Ocorrência 7:}

Original: Sensô no sanka o wasurezu kataritsugi, kako no kyôkun o ikashite heiwa no tame ni chikara o tsukusu koto wa hijô ni taisetsuna koto to omoimasu.

Tradução oficial: $\underline{I}$ believe it very important that we never forget to hand down our experiences of the horrors of war to future generations, and do our utmost to work for peace on the basis of the lessons of the past. (Questão 3, 1999)

Proposta de tradução para português: Acho que é de extrema importância que façamos esforços pela paz, relembrando e transmitindo [para as futuras gerações] nossa participação na guerra e fazendo uso das lições do passado. (Grifo nosso)

\section{Ocorrência 8:}


Original: Toku ni sensô ni yotte genshi bakudan no higai o uketa kuni wa Nihon dake deari, sono kyôretsuna hakairyoku to nagaku tsuzuku hôshanô no eikyô no osoroshisa o sekai no hitobito ni mo shikkari to rikaishite morau koto ga, sekai no heiwa o mezasu imi ni oitemo kiwamete jûyôna koto to omoimasu.

Tradução oficial: Japan is the only country to have suffered the damage of the atomic bomb in a war, and it is extremely important, in aiming for world peace, to let the people of the world understand clearly the terror of the tremendous destructive power and the long-enduring effects of radiation these weapons bring. (Questão 3, 1999)

Proposta de tradução para português: Mais especificamente, o Japão foi o único país a sofrer com os danos da bomba atômica em uma guerra e acredito ser de extrema importância que, ao se almejar a paz mundial, as pessoas ao redor do mundo façam um esforço para compreender esse poder fortemente destrutivo [da bomba] e os terrores do efeito da radiação, que permanecem ainda hoje. (Grifo nosso)

\section{Ocorrência 9:}

Original: Kono 10 nenkan ni sekai o mottomo ôkiku kaeta dekigoto wa, Sovieto Renpô no hôkai da to omoimasu.

Tradução oficial: $I$ think that the event which caused the greatest change in the world over the last decade was the collapse of the former Soviet Union. (Questão 4, 1999)

Proposta de tradução para português: Acho que o acontecimento que mais mudou o mundo nesses dez anos foi a dissolução da União Soviética.

\section{Ocorrência 10:}

Original: Sekai no kakuchi de funsô ga okori, ôku no inochi ga ushinawarete iru kyô, heiwa no taisetsusa o sekai no hitobito ga jûbun ni rikaisuru yô, Nihon no hitobito ga, tayumi naku doryokushite iku koto ga taisetsuna koto to omoimasu.

Tradução oficial: In the world of today where conflicts are occurring in various regions in which countless lives are lost, I believe it is very important for the people of Japan to ceaselessly strive to ensure that they themselves as well as the people of the world understand the importance of peace. (Questão 4, 1999)

Proposta de tradução para português: Nos dias de hoje, em que ocorrem conflitos em cada canto do mundo, onde várias vidas estão sendo perdidas, acho importante que os japoneses continuem se esforçando constantemente para que as pessoas ao redor do mundo entendam plenamente a importância da paz.

\section{Ocorrência 11:}

Original: Sorezore no hito no kazoku no kurushimi wa, ika bakari deatta ka to omoimasu.

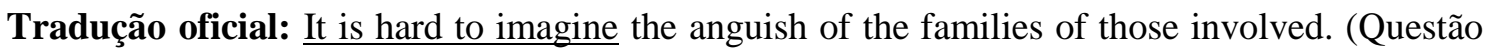
1, 2009)

Proposta de tradução para português: Imagino o quanto sofreram as famílias de cada uma dessas pessoas. 


\section{Ocorrência 12:}

Original: Sovieto Renpô ga happyôshita no wa sore yori ato no koto de, jiko no atta chiiki no hitobito no kenkô ni ataeta higai wa, issô ôkiku natta koto to omoimasu.

Tradução oficial: An announcement by the Soviet government took place only later and no doubt this delay resulted in further damage to the health of people in the affected regions. (Questão 1, 2009)

Proposta de tradução para português: Como o anúncio [do caso de Chernobyl] por parte da União Soviética só se deu mais tarde, acredito que os danos causados à sáude das pessoas na região do acidente foram muito maiores. (Grifo nosso)

\section{Ocorrência 13:}

Original: Kurô no ôi naka de, nôgyô, ringyô, suisangyô nado ni tazusawaru hitobito ga samazama ni kufû o korashi, sono bun'ya o mamoritsuzukete iru doryoku o tattoi mono ni omotte ori, maitoshi Nôrinsuisansai Tennôhai jushôsha ni oaisuru no o tanoshimi ni shite imasu.

Tradução oficial: I value highly the efforts made by all those engaged in agriculture, forestry and fisheries, who overcome many hardships by their imaginative solutions to the problems of maintaining their livelihoods. I look forward each year to meeting the awardees of the Emperor's Prize on the occasion of the annual Agriculture, Forestry and Fisheries Festival. (Questão 1, 2009)

Proposta de tradução para português: Considero valioso o esforço das pessoas envolvidas com a agricultura, a silvicultura e a pesca e que se esforçam criativamente para solucionar os diversos problemas, continuando a preservar essas atividades. Todo ano aguardo ansiosamente para conhecer os vencedores do Prêmio Imperial no Festival de Agricultura, Silvicultura e Pesca.

\section{Ocorrência 14:}

Original: Kôi no keishô to iu ten de, Kôshitsu no genjô ni tsuite wa, shitsumon no tôri da to omoimasu.

Tradução oficial: Concerning the continuity of the throne, I think the situation of the Imperial Family is as described in the question. (Questão 2, 2009)

Proposta de tradução para português: No que diz respeito à sucessão ao trono imperial, acho que a presente situação da Casa Imperial é conforme consta na pergunta.

\section{Ocorrências 15 e 16:}

Original: Kôi keishô no seido ni kakawaru koto ni tsuite wa, Kokkai no rongi ni yudaneru beki dearu to omoimasu ga, shôrai no Kôshitsu no arikata ni tsuite wa, Kôtaishi to sore o sasaeru Akishino no Miya no kangae ga sonchôsareru koto ga jûyô to omoimasu.

Tradução oficial: $\underline{I}$ think the issues concerning the system of Imperial succession should be left to the deliberation in the Diet, but concerning the ideal role of the Imperial Family in the future, I think it is important that the views of the Crown Prince and Prince Akishino, who supports him, are respected. (Questão 2, 2009)

Proposta de tradução para português: Sobre o que diz respeito ao sistema de sucessão ao trono imperial, acredito se tratar de um assunto que deve ser confiado à deliberação na Dieta Nacional, mas, no que tange ao papel da Casa Imperial no futuro, acho que é importante que se respeitem os pontos de vista do Príncipe Herdeiro e do Príncipe Akishino, que o apoia. 


\section{Ocorrência 17:}

Original: Kako no rekishiteki jijitsu o jûbun ni shitte mirai ni sonaeru koto ga taisetsu to omoimasu.

Tradução oficial: $\underline{I}$ believe it is essential for us to learn from the historical facts and prepare ourselves for the future. (Questão 3, 2009)

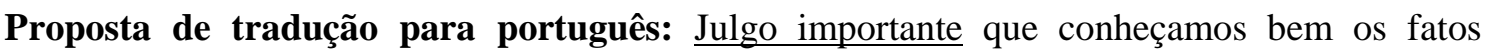
históricos do passado e que nos preparemos para o futuro.

\section{Ocorrência 18:}

Original: Kono futan no keigen to iu koto wa, kotoshi 1 nen sono hôkô de okonawaremashite, yahari futan no keigen to iu imi wa atta no dewanai ka to omotte imasu.

Tradução oficial: There has been a reduction in official duties over the past year and $\underline{I}$ think that this did indeed have the effect of lessening my burden. (Questão relacionada, 2009)

Proposta de tradução para português: Houve uma diminuição das minhas atividades oficiais nesse último ano e fico pensando se essa redução não teve de fato o efeito esperado.

\section{Ocorrência 19:}

Original: Tada, mada suwaru to iu koto ga dekinai no de, mada shibaraku wa suwaru koto, tatoeba Kashiko Dokoro nado suwaranakereba naranai tokoro no omairi wa, kore wa mada shibaraku muri dewanai ka to omotte imasu.

Tradução oficial: However, she still cannot sit on her heels in the formal Japanese style, so $\underline{I}$ think it will not be possible for her to participate in official duties that require her to sit in this way, such as at the Kashiko Dokoro (Palace Sanctuary) for a while longer. (Questão relacionada, 2009)

Proposta de tradução para português: No entanto, como [a Imperatriz] ainda não consegue se sentar, fico pensando se não seria impossível, ainda por um tempo, visitar lugares que requerem que ela se sente [no estilo formal japonês], como, por exemplo, no Kashiko Dokoro [Santuário do Palácio]. (Grifo nosso)

Quadro 2: Resumo das ocorrências de omou expressando julgamento

\begin{tabular}{|l|l|l|}
\hline Ocorrência & Sentido em japonês & Sentido em inglês \\
\hline 1 & Opinião pessoal & Constatação (mais generalizada) \\
\hline 2 & Opinião pessoal & Opinião pessoal \\
\hline 3 & Opinião pessoal & Constatação (mais enfática) \\
\hline 4 & Opinião pessoal (mais enfática) & Opinião pessoal \\
\hline 5 & Opinião pessoal (mais enfática) & Opinião pessoal \\
\hline 6 & Opinião pessoal & Opinião pessoal (mais emotiva) \\
\hline 7 & Opinião pessoal & Opinião pessoal \\
\hline 8 & Opinião pessoal & Constatação (mais generalizada) \\
\hline 9 & Opinião pessoal & Opinião pessoal \\
\hline 10 & Opinião pessoal & Opinião pessoal (mais enfática) \\
\hline 11 & Opinião pessoal (mais emotiva) & Constatação (mais generalizada) \\
\hline 12 & Opinião pessoal & $\begin{array}{l}\text { Constatação (mais enfática e mais } \\
\text { generalizada) }\end{array}$ \\
\hline
\end{tabular}




\begin{tabular}{|l|l|l|}
\hline 13 & Opinião pessoal & Afirmação (mais enfática) \\
\hline 14 & Opinião pessoal & Opinião pessoal \\
\hline 15 & Opinião pessoal & Opinião pessoal \\
\hline 16 & Opinião pessoal & Opinião pessoal \\
\hline 17 & Opinião pessoal & Opinião pessoal (mais enfática) \\
\hline 18 & Opinião pessoal & Opinião pessoal (mais enfática) \\
\hline 19 & Opinião pessoal & Opinião pessoal (mais enfática) \\
\hline
\end{tabular}

De modo geral, no que tange às alocuções que expressam opiniões e impressões do Imperador do Japão, as diferenças mais significativas entre as alocuções originais em japonês e a tradução para o inglês dizem respeito à ênfase, à generalização e à assertividade das opiniões. Como comentando anteriormente, consta em Makino e Tsutsui (2003, p. 52) que os japoneses costumam ser menos categóricos e assertivos em sua argumentação. Essa característica, em alguns casos destacados na presente pesquisa, parece estar muitas vezes perdida na versão em inglês das alocuções do Imperador. Nela, Akihito soa bem mais categórico, assertivo e enfático em suas opiniões, constrastando com a observação dos autores supracitados e podendo sugerir uma imagem mais ocidentalizada desse Imperador, no sentido em que a atenuação dos argumentos representa uma característica cultural japonesa. Consta também, na tradução, maior generalização dos argumentos, o que sugere menos comprometimento com o que é dito (já que muitas vezes não se fala em primeira pessoa) e consequente distanciamento.

Nas alocuções em japonês, no entanto, percebe-se maior constância no tom argumentativo de Akihito, tom esse de natureza predominantemente atenuante. Conferese também um caráter mais pessoal (fala em primeira pessoa) nas alocuções, sugerindo um tom de confissão e de consequente proximidade por parte do Imperador com o povo, o que pode criar maior identificação entre nação e monarca.

Sob uma ótica foucaultiana, tanto a atenuação de opiniões e consequente aproximação entre Akihito e o povo japonês, quanto a versão mais assertiva das alocuções do Imperador para a comunidade internacional, se configuram em estratégias de poder horizontais que se mostram eficazes a partir de um agenciamento de práticas e saberes; em outras palavras, a atenuação se mostra pertinente para a sociedade nipônica, mas não necessariamente tem a mesma força em relação a sociedades que valorizem um posicionamente mais firme de seu enunciador.

E novamente, os resultados também podem ser interpretados à luz das considerações de "autoritarismo amigável" de Sugimoto, reafirmando a noção de vigilância e controle por meio de uma moral, ou seja, por meio do tom que se espera do enunciador, o que varia de cultura para cultura.

\section{5) Considerações finais}

Com base nas análises acima, verificou-se que nas ocorrências de omou expressando sentimento há maior expressão de desejos e sentimentos nas alocuções em 
japonês, sugerindo maior envolvimento do Imperador com seus coenunciadores e criando, assim, uma imagem de um Akihito amigo do povo. Por outro lado, a versão em inglês apresenta menos emotividade, porém maior ênfase e assertividade no modo de dizer, o que sugere um monarca menos emotivo e mais firme, portanto mais distante sentimentalmente de seu povo.

Nas ocorrências de omou expressando julgamento e opinião, constatou-se que, em japonês, há maior atenuação daquilo que é dito, bastante comum aos japoneses quando argumentam e expressam suas opiniões, evitando muita asserção e ênfase, o que sugere, então, maior identificação entre Imperador e povo japonês. Já na versão em inglês, apreende-se um Akihito de etos um tanto mais categórico e enfático, além de, por vezes, sugerir opiniões menos pessoais e mais senso comum. É possível, portanto, se pensar em uma imagem mais ocidentalizada desse Imperador, uma vez que o caráter atenuante comum aos japoneses parece se diluir nas traduções.

Nesse sentido, pode-se falar de duas imagens, de dois etos diferentes desse mesmo enunciador. Por um lado, temos um Akihito mais sensível e amigo do povo japonês, com opiniões moderadas, criando identificação com a nação que representa. Por outro lado, confere-se um Akihito mais firme e categórico, portanto mais distante do modo de ser japonês, criando possivelmente maior identificação com a comunidade internacional.

Pode-se concluir, assim, que o etos de Akihito varia de acordo com seus coenunciadores. A imagem que o coenunciador que domina a língua japonesa cria desse Imperador que enuncia parece não ser a mesma que a comunidade internacional falante de inglês pode apreender do monarca a partir de suas alocuções.

Levando em consideração os conceitos de relações de poder e de "autoritarismo amigável", conclui-se que o contraste entre as duas versões das alocuções de Akihito ilustram diferenças culturais e de valores, o que muda a forma de recepção e apreensão de um tom do enunciador. A teoria de Sugimoto se justifica na medida em que caracteriza aspectos da sociedade japonesa, exemplificando que estratégias de um "poder sutil" se encontram vigentes no Japão, como a vigilância entre os membros da sociedade, a correção moral dos indivíduos etc. O Imperador, também inserido nessa rede de poderes e saberes, precisa estar em consonância com esse modo de ser, de sentir e de pensar nipônico, de forma que o exercício de sua função enquanto símbolo se mostre eficiente.

No que tange à ótica foucaultiana de poder, também se pode aplicá-la na sociedade japonesa, na medida em que se compreende o caráter horizontal (“autoritarismo amigável”), disciplinante, econômico e vigilante das relações de poder. Sendo Akihito o símbolo da nação e da união do povo, segundo a Constituição, é possível sugerir, por meio das análises, que seu papel enquanto símbolo da comunidade nipônica precisa se dar de forma eficaz, o que pode se concretizar mais facilmente a partir de uma maior aproximação entre monarca e povo. Tal proximidade parece garantir a manutenção de uma ordem social, pautada no incentivo ao trabalho e no controle dos corpos, ordem essa sustentada em uma rede de vigilância constante bem 
estruturada por meio de dispositivos de "poderes sutis", mantendo a ordem econômica capitalista vigente.

Por fim, julga-se importante destacar aqui que o caráter qualitativo da presente pesquisa permite ao seu autor que interprete os resultados de análise a partir de seu ponto de vista e entendimento de mundo. Não se tratam, portanto, de verdade absolutas, mas de impressões a partir de interpretações justificadas dos resultados obtidos.

\section{Referências}

BIRTH OF THE CONSTITUTION OF JAPAN. The Constitution of Japan. Disponível em: <http://www.ndl.go.jp/constitution/e/etc/c01.html>. Acesso set. 2014.

ESTUDOS JAPONESES. São Paulo: Oficina Editorial, 1979-. ISSN: 1413-8298.

FIELD, Norma. In the Realm of a Dying Emperor: a Portrait of Japan at Century's End. New York: First Vintage Books, 1993.

FOUCAULT, Michel. O sujeito e o poder. In: DREYFUS, Hubert; RABINOW, Paul. Michel Foucault, uma trajetória filosófica: para além do estruturalismo e da hermenêutica. Tradução Vera Porto Carrero. Rio de Janeiro: Forense Universitária, 1995.

Vigiar e punir: nascimento da prisão. $38^{\mathrm{a}}$ ed. Tradução Raquel Ramalhete. Petrópolis: Vozes, 2010.

IMPERIAL HOUSEHOLD AGENCY. Disponível em: <http://www.kunaicho.go.jp> Acesso set. 2014.

KURIHARA, Akiko; NISHIZAWA, Hiroko. Breve história do Japão. São Paulo: Empresa Jornalística Internacional Press Brasil, 2009.

MAINGUENEAU, Dominique. Ethos, cenografia, incorporação. In: AMOSSY, Ruth (org.). Imagens de si no discurso: a construção do ethos. $2^{\text {a }}$ ed. São Paulo: Contexto, 2011.

MAKINO, Seiichi; TSUTSUI, Michio. A Dictionary of Intermediate Japanese Grammar. 23 ${ }^{\mathrm{a}}$ ed. Tóquio: The Japan Times, 2003.

MARTIN, Peter. The Chrysantemum Throne: A History of the Emperors of Japan. Honolulu: University of Hawai'i Press, 1997.

PEREZ, Raphael dos Santos Miguelez. O etos de Akihito: uma análise discursiva de alocuções do Imperador do Japão. 2013. 132 f. Dissertação (Mestrado em Linguística) Instituto de Letras, Universidade do Estado do Rio de Janeiro, Rio de Janeiro, 2013.

SUGIMOTO, Yoshio. An Introduction to Japanese Society. Cambridge: Cambridge University Press, 1997. 